\title{
Whole Genome Sequence Analysis of Brucella abortus Isolates from Various Regions of South Africa
}

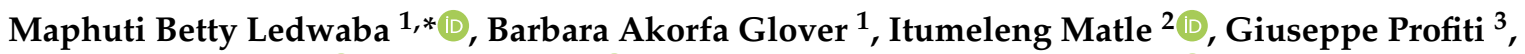 \\ Pier Luigi Martelli ${ }^{3}{ }^{\oplus}$, Rita Casadio ${ }^{3}{ }^{(0}$, Katiuscia Zilli $^{4}$, Anna Janowicz ${ }^{4}{ }^{\circ}$, Francesca Marotta ${ }^{4}(\mathbb{0}$, \\ Giuliano Garofolo ${ }^{4}$ and Henriette van Heerden ${ }^{1, * \mathbb{D}}$ \\ 1 Department of Veterinary Tropical Diseases, Faculty of Veterinary Science, University of Pretoria, \\ Onderstepoort, Pretoria 0110, South Africa; realrhema@gmail.com \\ 2 Bacteriology Division, ARC-Onderstepoort Veterinary Research, Onderstepoort, Pretoria 0110, South Africa; \\ MatleI@arc.agric.za \\ 3 Bologna Biocomputing Group, University of Bologna, I-40126 Bologna, Italy; \\ giuseppe.profiti2@unibo.it (G.P.); gigi@biocomp.unibo.it (P.L.M.); rita.casadio@unibo.it (R.C.) \\ 4 National and OIE Reference Laboratory for Brucellosis, Experimental Zooprophylactic Institute of Abruzzo \\ and Molise Giuseppe Caporale, 64100 Teramo, Italy; k.zilli@izs.it (K.Z.); a.janowicz@izs.it (A.J.); \\ f.marotta@izs.it (F.M.); g.garofolo@izs.it (G.G.) \\ * Correspondence: ledwababetty@gmail.com (M.B.L.); henriette.vanheerden@up.ac.za (H.v.H.)
}

\section{check for} updates

Citation: Ledwaba, M.B.; Glover, B.A.; Matle, I.; Profiti, G.; Martelli, P.L.; Casadio, R.; Zilli, K.; Janowicz, A.; Marotta, F.; Garofolo, G.; et al. Whole Genome Sequence Analysis of Brucella abortus Isolates from Various Regions of South Africa. Microorganisms 2021, 9, 570. https:// doi.org/10.3390/microorganisms 9030570

Academic Editor: Pablo V. Yagupsky

Received: 30 November 2020

Accepted: 15 February 2021

Published: 11 March 2021

Publisher's Note: MDPI stays neutral with regard to jurisdictional claims in published maps and institutional affiliations.

Copyright: (c) 2021 by the authors. Licensee MDPI, Basel, Switzerland. This article is an open access article distributed under the terms and conditions of the Creative Commons Attribution (CC BY) license (https:/ / creativecommons.org/licenses/by/ $4.0 /)$.

\begin{abstract}
The availability of whole genome sequences in public databases permits genome-wide comparative studies of various bacterial species. Whole genome sequence-single nucleotide polymorphisms (WGS-SNP) analysis has been used in recent studies and allows the discrimination of various Brucella species and strains. In the present study, 13 Brucella spp. strains from cattle of various locations in provinces of South Africa were typed and discriminated. WGS-SNP analysis indicated a maximum pairwise distance ranging from 4 to 77 single nucleotide polymorphisms (SNPs) between the South African Brucella abortus virulent field strains. Moreover, it was shown that the South African B. abortus strains grouped closely to B. abortus strains from Mozambique and Zimbabwe, as well as other Eurasian countries, such as Portugal and India. WGS-SNP analysis of South African B. abortus strains demonstrated that the same genotype circulated in one farm (Farm 1), whereas another farm (Farm 2) in the same province had two different genotypes. This indicated that brucellosis in South Africa spreads within the herd on some farms, whereas the introduction of infected animals is the mode of transmission on other farms. Three B. abortus vaccine S19 strains isolated from tissue and aborted material were identical, even though they originated from different herds and regions of South Africa. This might be due to the incorrect vaccination of animals older than the recommended age of 4-8 months or might be a problem associated with vaccine production.
\end{abstract}

Keywords: bovine brucellosis; Brucella abortus; whole genome sequence; single nucleotide polymorphisms; comparative analysis

\section{Introduction}

The genus Brucella is a highly monomorphic genus comprised of gram-negative pathogenic species [1] affecting a wide range of hosts, including humans. Insufficient progress has been achieved in the identification of species within this genus, since their homogeneity has compromised discrimination, especially when using molecular typing tests. The introduction of newly described atypical Brucella species extended the level of diversity within the genus [2-6]. For instance, Brucella spp. isolated from amphibians are reported to be motile, despite the fact that the genus historically consists of non-motile species [6-8]. Species from this genus cause varying disease spectra with the collective name brucellosis. Although the infection has been eradicated in most developed and industrialized countries, it is still widely endemic elsewhere and contributes to massive economic losses, as well as 
veterinary and public health distress in many countries, especially those located in Africa, Central Asia, and the Middle East and some countries of the European Mediterranean area $[9,10]$. Brucella abortus, which is the causal agent of bovine brucellosis, affects the Bovidae family and its natural reservoir hosts include cattle (Bos taurus), African buffalo (Syncerus caffer), water buffalo (Bubalus bubalis), elk (Cervus canadensis), and American bison (Bison bison) [11]. Regardless of the host preference within the genus, it is evident that species can also affect hosts other than their preferred ones, especially if there is a close interaction between animals [12-14]. Therefore, it is crucial to accurately understand the inter-species relationships of the genus Brucella, in order to comprehend the complete epidemiology of the disease [15]. Even though there is no assay that can solely diagnose brucellosis accurately, except for the gold standard (culturing), a number of molecular assays that allow the differentiation of Brucella spp. and their biovars, as well as tracing back the source of the outbreak, have been reported [16-21].

Brucellosis is a notifiable disease in South Africa (SA) and is controlled according to the Animal Disease Act 35 of 1984 . Bovine brucellosis is controlled based on the bovine brucellosis scheme (R.2483 of 9 Dec 1988) established under Section 10 of Act 35. The scheme involves the vaccination of heifer aged between 4 and 8 months with a $5 \times 10^{10}$ organisms of Brucella abortus S19 vaccine and serological testing of high-risk herds that are suspected of or have been confirmed as being infected. The government continuously encourages farmers to participate in the scheme; however, it is voluntary. Moreover, the scheme is under review and several amendments, which include the compulsory participation of all animal owners and livestock, reporting of any abortion cases within the herd, etc., have been suggested [22]. This document also emphasizes that "to date, there are limited recent empirical data or published reports on the existence or prevalence of brucellosis in the livestock industry in South Africa". Furthermore, it indicates that farmers buying replacement stock may be at risk of introducing infected animals to their herd since most farmers are not complying with the bovine brucellosis regulations. Ninety percent (90\%) of bovine brucellosis infections in South Africa are reported [23] to be caused by $B$. abortus bv. 1 , while $10 \%$ are due to B. abortus bv. 2. In addition, the 2015-2016 Gauteng Province Veterinary Services Annual Report [24] showed a sero-prevalence of $1.27 \%(30 / 2359)$ in the province when testing bovine brucellosis with the rose Bengal test (RBT) and complement fixation test (CFT). Therefore, initial steps that may help in the eradication of brucellosis include the identification of strains occurring in the country, host species, and sources of infection. Moreover, it will be essential to determine whether the same strains are circulating within the source of infection regions to avoid misinterpretation of the situation.

Whole genome sequence-single nucleotide polymorphisms (WGS-SNP) analysis was used in the present study, based on previous reports demonstrating its efficacy in the discrimination of various conserved Brucella strains and biovars [25-27]. In addition, a single nucleotide polymorphism (SNP) microarray was previously used to establish the evolutionary lineage of Brucella spp. by distinguishing the major clades of B. abortus, $B$. melitensis, and B. suis and assigning the strains to their designated lineages [28]. The analysis of raw data generated from sequencing with different platforms has improved due to the available bioinformatics tools, which have helped in the achievement of novel discoveries and clarification of most biological processes, leading to accurate results $[29,30]$. Variant calling tools used during the WGS-SNP analysis must include parameters that will allow for errors encountered during the data preparation, which include amplification biases and machine and software errors encountered during sequencing and sequence mapping/alignment [31], but the choice of the variant tool essentially depends on the study aims and objectives. Moreover, the reference genome chosen for use in WGS-SNP analysis should be considered as it can crucially influence the output number of SNPs, which in turn will affect the accuracy of the overall phylogenetic relationships [32]. Several studies have reported the use of SNP analysis in successfully discriminating between $B$. melitensis strains, as well as determining their geographic and global distribution $[26,33,34]$. The 
above authors [33] also reported that the WGS-SNP-based analysis used in their study to determine the phylogenetic relatedness of $B$. melitensis has a better resolution in grouping the strains into their specific genotypes based on their geographic distribution. Therefore, the current study also used WGS-SNP analysis to determine the relationship and genetic variation of $B$. abortus strains that exist within a single herd (farm) and between various herds in SA. Strains from two farms (Farm 1 and Farm 2) and some of those submitted to the Agricultural Research Council-Onderstepoort Veterinary Research (ARC-OVR) for routine screening were used and compared with global sequences available online. Strains from ARC-OVR are grouped under the name "other" in the generated trees since they are isolated from samples submitted at the national reference laboratory from different regions throughout SA.

\section{Materials and Methods}

\subsection{Samples and Sample Area}

Milk samples were collected opportunistically by animal health technicians during routine brucellosis eradication visits at the identified farms. Farm 1 and Farm 2 were considered brucellosis-infected herds because they had a history of brucellosis following repeated sampling by Gauteng Department of Agriculture and Rural Development (GDARD) animal health technicians and screening with serum agglutination test (SAT), RBT, and CFT at ARC-OVR. Complete random sampling of animals aged 18 months and above was applied to avoid false positive reactions that might result from vaccination since heifers at the farms are vaccinated at 4-8 months of age with the B. abortus S19 vaccine. Some of the samples were collected from previously identified (C-branded) seropositive animals, which are those that tested positive for RBT and CFT during a previous state veterinary surveillance and control program and were to be culled. Approximately $20 \mathrm{~mL}$ of milk was collected from each teat in a sterile tube and transported on ice to the Faculty of Veterinary Sciences, Department of Veterinary Tropical Diseases' bacteriology laboratory for culturing. Brucella cultures from Farms 1 and 2 were submitted to ARC-OVR for biotyping [35] using standard microbiology procedures [36]. More strains were isolated and biotyped at ARC-OVR from tissue samples submitted for routine screening from different provinces and regions of South Africa. Briefly, isolates were biotyped based on their colony morphology; agglutination on anti-Brucella mono-specific sera abortus and melitensis; reaction to oxidase, urease, and catalase tests; production of hydrogen sulphide; growth in the absence of carbon dioxide; growth in the presence of basic fuchsin and thionin dyes; lysis by different phages (Tbilisi; Weybridge; Izatnagar strain 1; Berkeley strain 2); and inhibition by erythritol $(1000 \mu \mathrm{g})$ and antibiotics (Streptomycin $10 \mu \mathrm{g}$, Penicillin G 10 units, and Rifampicin $30 \mu \mathrm{g})(35,36)$. A Brucella abortus str. 544 culture was used as a control in all the phenotypic tests.

\subsection{Bacterial Strains, DNA Extraction, Quantification, and Molecular Identification}

Milk samples collected from infected bovine herds in different provinces of South Africa were cultured with modified-Agrifood Research and Technology Center of Aragon (M-CITA) [35] for bacterial isolation. DNA was extracted with the High Pure PCR Template Preparation Kit (Roche Products Pty (Ltd.), Midrand, South Africa) from positive culture plates according to the manufacturer's instructions. It was then quantified with multivolume plate nanodrop analysed with the Take3 Session (BioTek Instruments, Thermo Fisher Scientific, Centurion, South Africa). A representative that consisted of 13 B. abortus strains was randomly selected and sequenced (Tables 1 and 2). From the total strains isolated and selected for sequencing, three strains were isolated from samples collected at Farm 1 and two from Farm 2, while the others were isolated from samples submitted to ARC-OVR for routine screening from different provinces and regions of SA (Table 2). Moreover, they are dairy farms in Gauteng province, identified as brucellosis-infected farms by the animal health technician and state veterinarian working in the area. The farms have no record of trade between each other. All isolates used in the study were differentiated with 
species-specific abortus-melitensis-ovis-suis (AMOS) [16] and Bruce-ladder [18] multiplex polymerse chain reaction (PCR) assays, following the protocol described elsewhere. SAUK6 was isolated in a later stage in the study and identified as Brucella spp. using the Brucella genus-specific 16 S-23 S rRNA interspace (ITS) PCR [37]. It was included in the sequencing list after the biotyping results at ARC-OVR indicated that it was B. abortus S19.

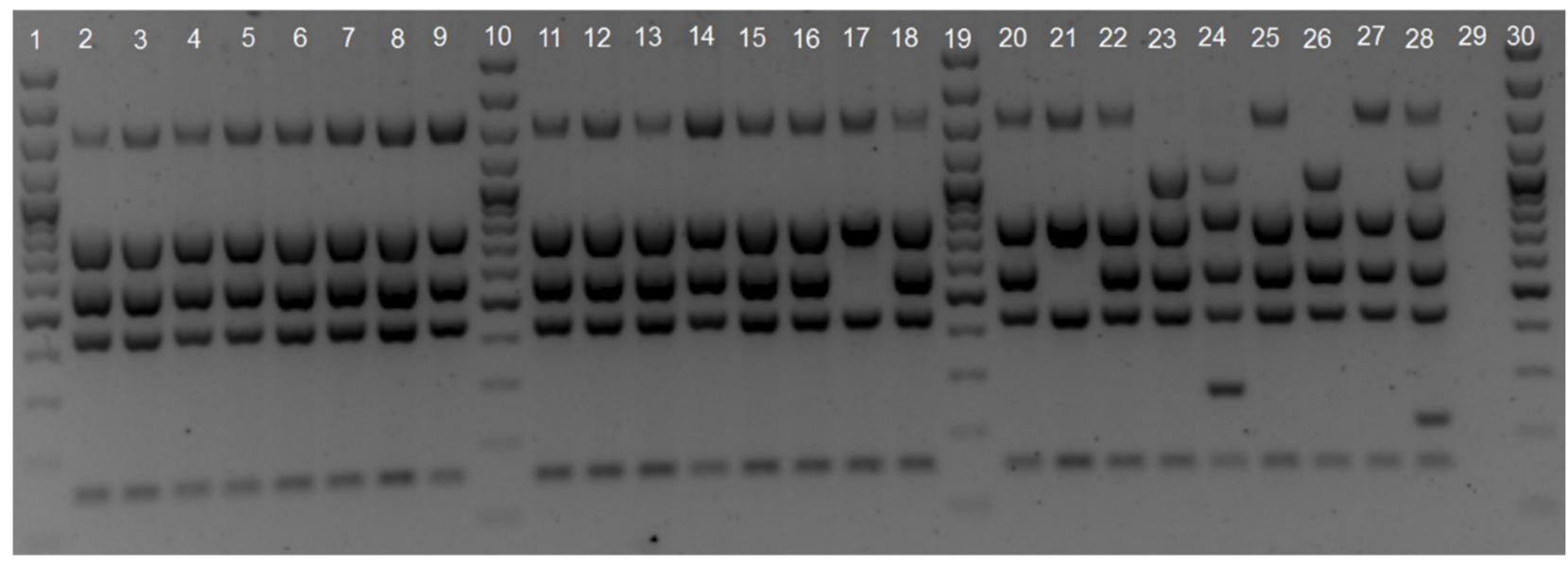

(A)

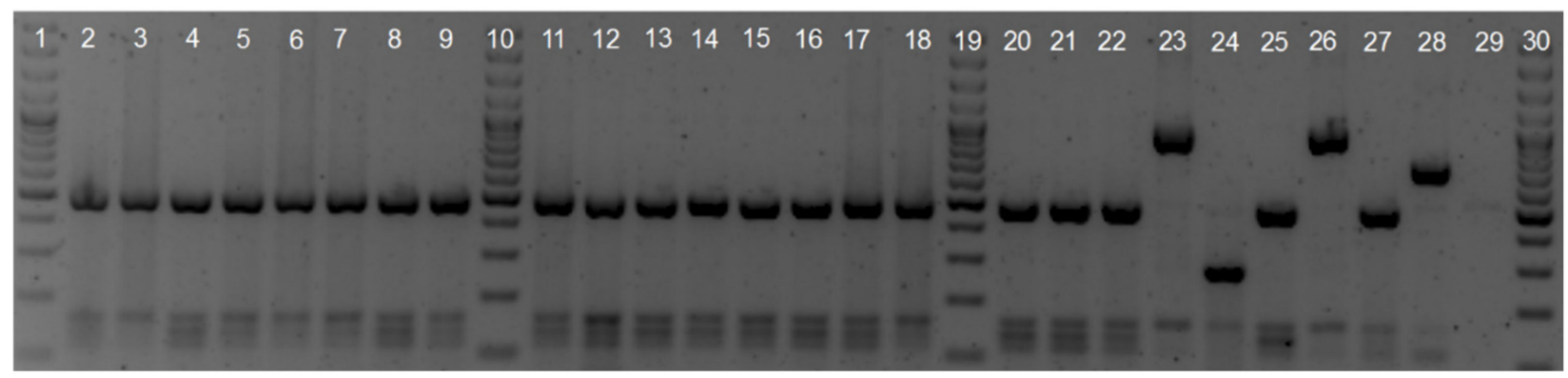

(B)

Figure 1. Gel images of Bruce-ladder (A) and AMOS (B) multiplex PCR assays. Descriptive information is given in Table S1.

Table 1. A list indicating the old sample names, new assigned sample names, and accession numbers of South African Brucella abortus strains characterized in this study.

\begin{tabular}{ccc}
\hline Current Sample Name $^{\mathbf{a}}$ & Old Sample Name $^{\mathbf{b}}$ & Accession Numbers \\
\hline B. $a$ abor_UP-Jersey & SA-JERSEY & SAMN15685093 \\
B. $a$ abor_UP-594 & SA-594 & SAMN15685094 \\
B. abor_UP-1258 & SA-1258 & SAMN15685095 \\
B. abor_UP-S51 & SA-S51 & SAMN15685096 \\
B. abor_UP-97 & SA-97 & SAMN15685097 \\
B. abor_UP-4408 & SA-4408 & SAMN15685098 \\
B. abor_UP-5423 & SA-S5423 & SAMN15685099 \\
B. abor_UP-5706/2 & SA-5706/2 & SAMN15685100 \\
B. abor_UP-5513 & SA-5513 & SAMN15685101 \\
B. abor_UP-A5569 & SA-A5569 & SAMN15685102 \\
B. abor_UP-A5672 & SA-A5672 & SAMN15685103 \\
B. abor_UP-A5685 & SA-A5685 & SAMN15685104 \\
B. abor_UP-UK6 & SA-UK6 & SAMN15685105 \\
\hline
\end{tabular}

a The old sample names used in Figure 1. ${ }^{\mathrm{b}}$ The new assigned names used in Figure 2. 


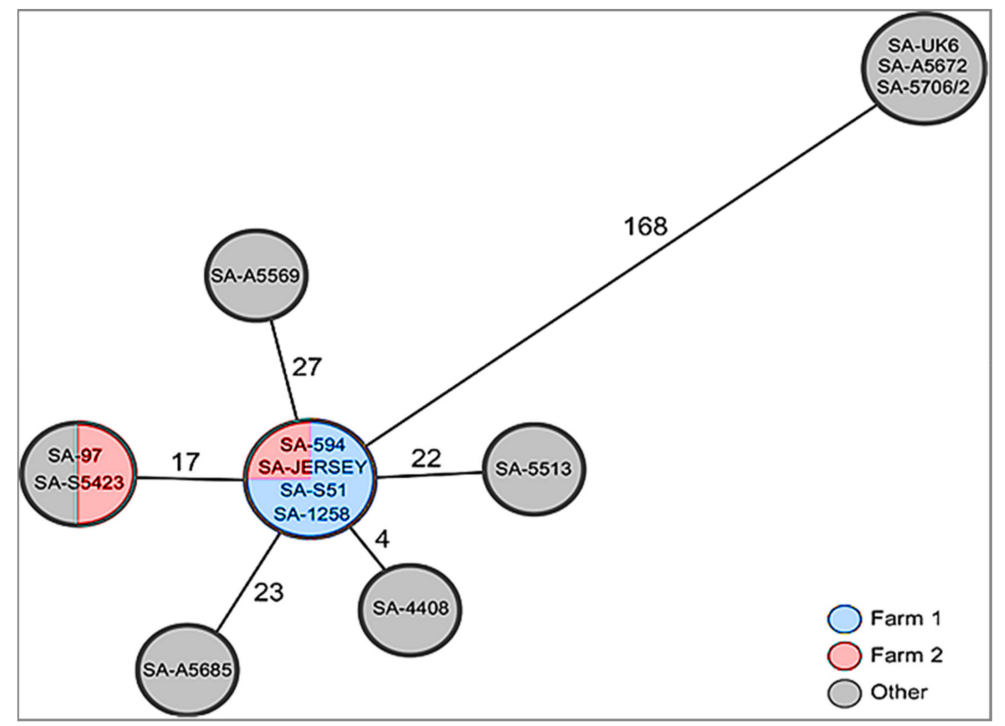

Figure 2. Minimum spanning tree of 13 South Africa (SA) strains depicting the connection between Farm 1 (shown with a blue background), Farm 2 (shown with a pink background), and isolates from the Agricultural Research Council-Onderstepoort Veterinary Research (ARC-OVR) (shown with a gray background). It also shows significant variation (168 single nucleotide polymorphisms (SNPs)) between the field and vaccine strains.

\subsection{Whole-Genome Sequencing}

Isolates were sequenced with the Illumina NextSeq 500 platform with 150 bp pairedend chemistry. The genome libraries were prepared with the Nextera XT Library Prep kit (Separations, Randburg, South Africa), according to the manufacturer's recommendations. Isolates were sequenced with Illumina's recommended dual index barcoding protocol, with the aim of obtaining a read coverage ranging from 18 to 356-fold, with an average of 155 -fold. Reads with a quality score of $<20$ and a length shorter than $70 \mathrm{bp}$, as well as a Phred mean quality of less than 24 , were trimmed at the $5^{\prime}$-end and $3^{\prime}$-end and poor quality reads were then discarded.

\subsection{WGS-SNP Data Analysis}

The sequences were assigned taxonomic identities using Kraken [38], which is a sequence classifier that queries the database of $k$-mers for exact-matches. Sequences were deposited in GenBank and assigned accession numbers, as shown in Table 1. In silico genotyper (ISG) version 0.16.10-3 [39] was used to identify the SNPs among the genomes. The ISG is an open source tool that identifies and annotates variants from nucleotide sequences. The current pipeline uses BWA-MEM (version 0.712-r1039) [40] for genome alignment and GATK version 3.9 [41] to call the SNPs. For comparative WGSSNP, we retrieved 175 currently available B. abortus genomes from GenBank [42] and selected B. melitensis 16M (Accession numbers: AE008917; AE008918) as the outgroup strain. Moreover, B. abortus strain 2308 (Accession numbers: NC_007618; NC_007624) was used as the reference for the SNPs calling alignment. For the SNPs calling process, default parameters were used to filter and remove duplicates, with the minimum quality set at Phred 30. From the generated output, clean unique variants were used to further analyze the sequences. Default parameters of the PHYLOViZ software version 2.0 [43] were used to generate maximum spanning trees (MST) with the SNP data of the South African strains, in order to determine the geographic distribution of the strains and possible connections between the localities. Furthermore, a phylogenetic tree was constructed with maximum parsimony in Phylogenetic Analysis Using Parsimony (PAUP) Software version 4.0b [44], using 600 bootstrap replicates to assess the branch support. Since the tree was bigger and unclear to read, smaller sections were snipped from the tree for clear visibility. 


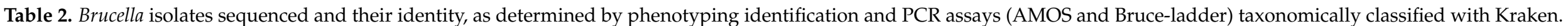

\begin{tabular}{|c|c|c|c|c|c|c|}
\hline Sample Name & Sample ID & Host & Sample Source & Country of Origin & Sample ID (Assay Used) & Kraken ID \\
\hline SA-JERSEY & 2017.TE.25009.1.1 & cattle & Milk & $\mathrm{SA}\left(\mathrm{F} 1^{\mathrm{a}}\right)$ & $\begin{array}{c}\text { B. abortus: AMOS, } \\
\text { Bruceladder; } \text { B. abortus bv. 1: } \\
\text { biotyping }\end{array}$ & B. abortus \\
\hline SA-594 & 2017.TE.25009.1.2 & cattle & Milk & $\mathrm{SA}\left(\mathrm{F} 1^{\mathrm{a}}\right)$ & $\begin{array}{c}\text { B. abortus: AMOS, } \\
\text { Bruceladder; } B \text {. abortus bv. 1: } \\
\text { biotyping }\end{array}$ & B. abortus \\
\hline SA-1258 & 2017.TE.25009.1.3 & cattle & Milk & $\mathrm{SA}\left(\mathrm{F} 1^{\mathrm{a}}\right)$ & $\begin{array}{c}\text { B. abortus: AMOS, } \\
\text { Bruceladder; } B \text {. abortus bv. 1: } \\
\text { biotyping }\end{array}$ & B. abortus \\
\hline SA-S51 & 2017.TE.25009.1.4 & cattle & Milk & $\mathrm{SA}\left(\mathrm{F} 2^{\mathrm{b}}\right)$ & $\begin{array}{c}\text { B. abortus: AMOS, } \\
\text { Bruceladder; } B \text {. abortus bv. 1: } \\
\text { biotyping }\end{array}$ & B. abortus \\
\hline SA-97 & 2017.TE.25009.1.5 & cattle & Milk & $\mathrm{SA}\left(\mathrm{F} 2^{\mathrm{b}}\right)$ & $\begin{array}{c}\text { B. abortus: AMOS, } \\
\text { Bruceladder; } \text { B. abortus bv. 1: } \\
\text { biotyping }\end{array}$ & B. abortus \\
\hline SA-4408 & 2017.TE.25009.1.7 & cattle & Tissue & SA (ARC-OVR) & $\begin{array}{c}\text { B. abortus: AMOS, } \\
\text { Bruceladder; } B \text {. abortus bv. 1: } \\
\text { biotyping }\end{array}$ & B. abortus \\
\hline SA- $5423^{c}$ & 2017.TE.25009.1.8 & cattle & Tissue & SA (ARC-OVR) & $\begin{array}{c}\text { B. abortus: AMOS, } \\
\text { Bruceladder; } B \text {. abortus bv. 1: } \\
\text { biotyping }\end{array}$ & B. abortus \\
\hline SA-5706/2 & 2017.TE.25009.1.9 & cattle & Tissue & SA (ARC-OVR) & $\begin{array}{c}\text { B. abortus S19 (AMOS; } \\
\text { Bruceladder, biotyping) }\end{array}$ & B. abortus \\
\hline SA-5513 & 2017.TE.25009.1.10 & cattle & Abomasal fluid & SA (ARC-OVR) & $\begin{array}{c}\text { B. abortus: AMOS, } \\
\text { Bruceladder; } B \text {. abortus bv. 2: } \\
\text { biotyping }\end{array}$ & B. abortus \\
\hline SA-A5569 & 2017.TE.25009.1.11 & cattle & Tissue & SA (ARC-OVR) & $\begin{array}{c}\text { B. abortus: AMOS, } \\
\text { Bruceladder; B. abortus bv. 2: } \\
\text { biotyping }\end{array}$ & B. abortus \\
\hline
\end{tabular}


Table 2. Cont.

\begin{tabular}{|c|c|c|c|c|c|c|}
\hline Sample Name & Sample ID & Host & Sample Source & Country of Origin & Sample ID (Assay Used) & Kraken ID \\
\hline SA-A $5672^{d}$ & 2017.TE.25009.1.12 & cattle & Tissue & SA (ARC-OVR) & $\begin{array}{c}\text { B. abortus S19 (AMOS; } \\
\text { Bruceladder, biotyping) }\end{array}$ & B. abortus \\
\hline SA-A5685 & 2017.TE.25009.1.13 & cattle & Tissue & SA (ARC-OVR) & $\begin{array}{c}\text { B. abortus: AMOS, } \\
\text { Bruceladder; } B \text {. abortus bv. 1: } \\
\text { biotyping }\end{array}$ & B. abortus \\
\hline SA-UK6 ${ }^{\mathrm{c}, \mathrm{f}}$ & 2017.TE.25008.1.10 & cattle & Aborted fetus & SA (ARC-OVR) & $\begin{array}{l}\text { Brucella spp. (ITS) }{ }^{\mathrm{e}} \\
\text { B. abortus S19 (biotyping) }\end{array}$ & B. abortus \\
\hline
\end{tabular}

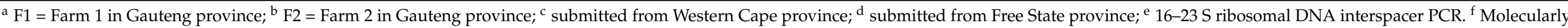
identified (ITS PCR) and biotyped at a later stage in the study. 


\section{Results and Discussion}

The isolates were speciated and characterized with a Bruce-ladder [18] (Figure 1A) and AMOS [16] (Figure 1B) multiplex assay alongside thirteen others that were not sequenced but tested with molecular assays. All of the isolates were biotyped at the ARC-OVR, with most identified as B. abortus bv. 1, two as B. abortus bv.2, and two as B. abortus S19, as shown on Table 2 and previously in Ledwaba et al. [35].

The Brucella strains sequenced in the present study were all classified as B. abortus (Table 2) by the Kraken taxonomic classifier. The tool only indicated that the sequences were $B$. abortus since its sensitivity is up to the genus level; thus, it cannot differentiate between the biovars and it cannot distinguish the vaccine strains from the virulent ones. Nonetheless, Wood and Salzberg [38] indicated that although Kraken is only genus-specific, it is quicker than most classifiers and its accuracy, which is capacitated by the growing number of sequences, is comparable to that obtained with BLAST.

A comparative analysis of the thirteen South African and 175 B. abortus genome assemblies retrieved from the National Centre for Biotechnology Information (NCBI) resulted in a total of 22,307 variants, of which 17,379 are clean unique variants (Table S2), which were used to generate the maximum spanning trees (MST). To determine the possible connection between the South African farms, the MST tree was generated with clean unique variants from only SA strains.

Figure 2 depicts a maximum pairwise distance ranging from 4 to $27 \mathrm{SNPs}$ between all the South African virulent field strains from Farm 1, Farm 2, and ARC-OVR. Several genotypes were observed between the South African field strains (Figure 2). However, the three B. abortus S19 vaccine strains isolated from tissue and aborted material showed that they are identical but different to the virulent strains, with a significant variation of 168 SNPs (Figure 2).

The minimum spanning and phylogenetic trees (Figures 2 and 3) generated with the WGS-SNP data respectively showed that all B. abortus bv. 1 strains from Farm 1 clustered together with one of the strains from Farm 2, whereas the SA-97 strain from Farm 2 clustered with the SA-5423 strain, although in one main group with the others (Figures 2 and 3C). This indicates that there was one clonal genotype circulating within Farm 1, while multiple genotypes were found within Farm 2. These farms are approximately $80 \mathrm{~km}$ from each other, with Farm 1 located in Springs and Farm 2 located in Bronkhorstspruit in Gauteng province.

Moreover, previous farm records showed that both farms were disease-free in the past years; thus, the isolated strains might have been introduced on the farms through the replacement stock brought in without knowledge of their brucellosis status. The presence of the same strain on both farms indicates that they may have introduced cattle from the same infected source. Additionally, the clustering of SA-97 from Farm 2 with SA-5423, which is one of the ARC-OVR strains, points out that this strain might be occurring and circulating on various farms around South Africa, since the institution (ARC-OVR) is a national reference laboratory and thus receives samples from all provinces.

Moreover, South African sequences did not cluster within the major lineages A and $\mathrm{B}$, despite the fact that most African isolates cluster to these lineages. However, they clustered with a few strains from African countries (Mozambique and Zimbabwe), as well as many strains from Eurasia (including Portugal and India). This was also previously shown in several molecular analysis studies that provided insight into the heterogeneity of B. abortus strains from Africa, Europe, Maghreb, and Sub-Saharan countries [45-47]. Additionally, it suggests that B. abortus might have spread into/out of South Africa as a result of socio-economic, migration, or colonization links between the countries in the past. Previous studies have also demonstrated that B. abortus isolates from sub-Saharan countries and those from Europe cluster together, even though heterogeneity within the clusters exists [48,49]. This was also shown in a study by Khames et al. [46], who indicated that Algerian B. abortus isolates used in their study clustered with those from Morocco, Zimbabwe, France, Germany, Portugal, and Italy. 


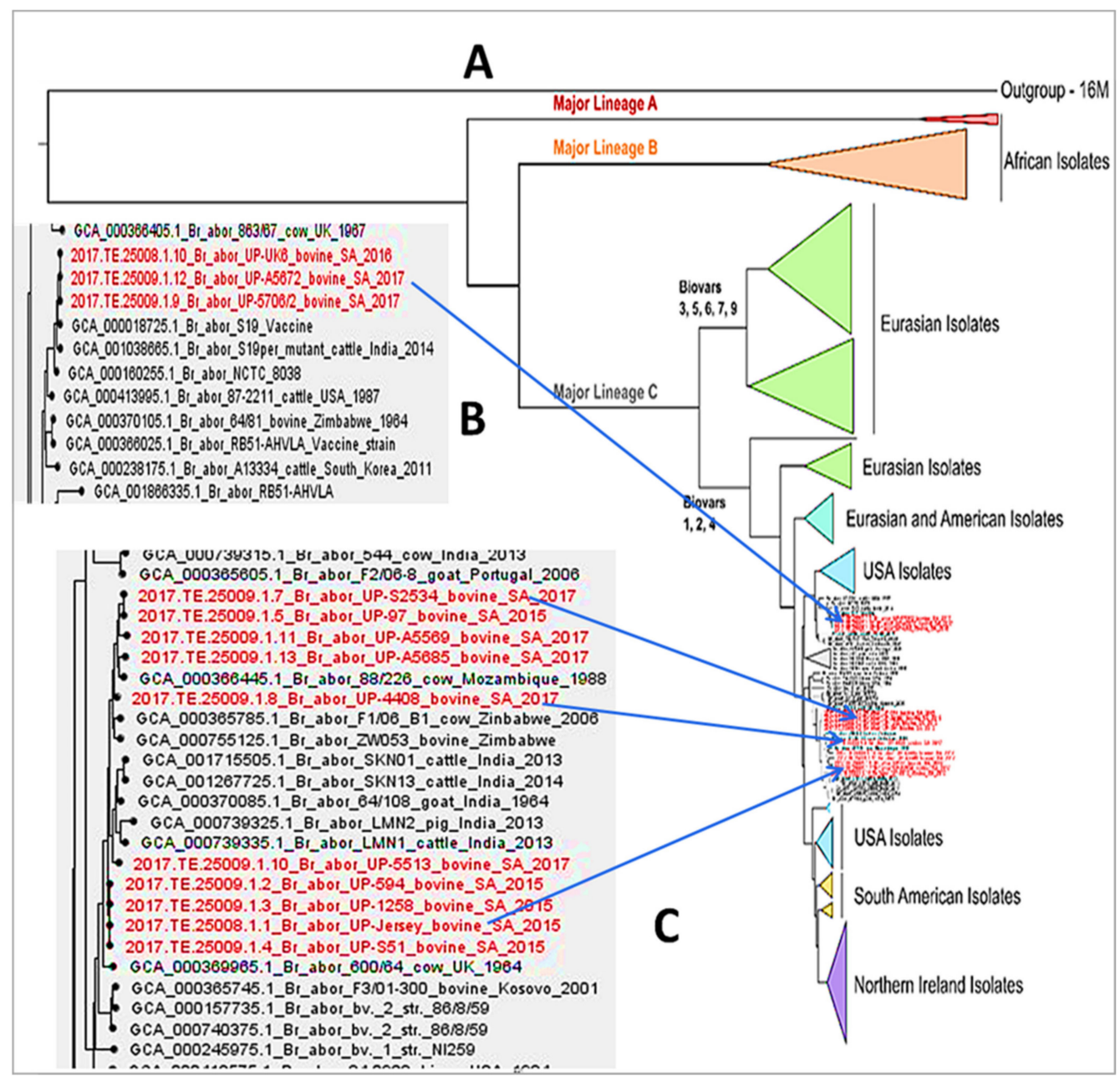

Figure 3. (A) A phylogenetic tree based on WGS-SNP depicting the relationship between 13 South African strains and 175 Brucella abortus genomes available online. The tree was generated with single nucleotide polymorphism (SNP) analysis using B. abortus bv. 1 strain 2308 as a reference and Brucella melitensis bv. 1 strain $16 \mathrm{M}$ as an outgroup. The labels in red on the tree (A) represent the South African strains. (B) A section cut from the original tree indicating the South African B. abortus S19 and its closely related strains. (C) A section also cut from the original tree illustrating South African B. abortus virulent strains and their closely related ones. NB: Strain S5423 (C) was incorrectly labelled as S2534.

Brucella abortus S19 vaccine strains isolated in this study grouped with B. abortus S19 per_mutant from India, as well as the B. abortus S19 reference strain (Figure 3B). Moreover, Figures 2 and 3B clearly show that the three SA B. abortus S19 strains are identical. This was unanticipated since they were isolated from tissue and aborted material in different provinces of South Africa (Gauteng and Western Cape provinces). This suggests that the vaccine used for immunization might be from the same batch, which had production problems, or that the cows were vaccinated, with a full dose given to heifers of 4-8 months while pregnant or at a later stage than recommended by the manufacturer. Moreover, it has been shown that 70\% of the cattle vaccinated with the B. abortus S19 live vaccine get protection against the virulent wild-type strains; however, the vaccine can also induce abortions if full doses are given to pregnant animals [50,51]. The isolation of clonal vaccine strains from livestock was also reported in a previous study in which two B. melitensis Rev. 1 isolates from sheep and two B. abortus RB51 isolates from bovine shared the same genotype and clustered with other available vaccine sequences of their type [52]. Previous studies $[53,54]$ indicated that the vaccination of pregnant cows with a dose of $5 \times 10^{10}$ of the attenuated B. abortus S19 vaccine has induced abortions in a significant number of vaccinated cows. Animals, mostly those vaccinated as adults, show persistent serological 
reactions against the antigenic O-chain of the lipopolysaccharide of the smooth Brucella strains [55]. In addition, a recent study showed that pregnant heifers vaccinated with a high dose of the B. abortus S19 vaccine displayed an increased body temperature within the first two days post vaccination [56]. Nevertheless, it was previously demonstrated that [57] the subcutaneous or conjunctival vaccination of animals with a reduced dose ranging from $3 \times 10^{8}$ to $5 \times 10^{9}$ can decrease the serological antibody response. In another study of Poester et al. [58], the low dose of $3 \times 10^{9}$ was used in adult animals and resulted in a no antibody response from all of the animals when tested with RBT nine months after vaccination.

WGS-SNP analysis has been previously used to discriminate between various homologous Brucella strains [24,25]. It can be effective in the discrimination and comparative analysis of closely related Brucella spp., provided there is enough data available for comparison $[25,59]$. SNP calling requires well-processed data and a robust calling tool that is user-friendly and easier to apply. Even though there are far fewer genomes available for SNP-based comparison studies than multi-locus variable numbers of tandem repeat multi locus variable number of tandem repeat anlysis (MLVA) allele profiles, WGS-SNP analysis can still provide a better resolution since polymorphism can be established from either the coding or non-coding regions [34]. The phylogenetic analysis of bacterial strains provides information that could help in the development of rapid diagnostic assays for epidemiology, as well as understanding the structure, genetic diversity, and evolutionary history of the strains in question [60]. Currently, MLVA and multilocus sequence typing (MLST) are used in the typing of Brucella species [19,46,61], and the availability of WGS in public repositories makes it possible to conduct genome-wide comparative studies of various bacterial species [34,62]. However, it is still complicated to perform phylogeographic categorization because of the speculative information about the pathogen's origin and the possible migration route [34,62]. Zaki and co-workers [63] reported that WGS-SNP-based analysis has proven to be a rapid tool for epidemiological studies and tracing outbreaks since it efficiently discriminated between 33 Brucella isolates by determining their native geographical origin based on spatial clustering. The reliability and reproducibility of SNP analysis were further shown in a study by Janowicz et al. (2018) [32], who indicated that it performed better than MLVA-16 and core genome multilocus sequence typing (cgMLST), even though there was little variation.

In the present study, the SNP analysis showed that it is a powerful tool to use in differentiating homogenous species. WGS-SNP analysis depicted that there is one clonal genotype circulating within Farm 1, but varying genotypes are present on Farm 2 . The occurrence of one genotype on both farms indicates that both farms may have unknowingly introduced the infection from the same source, where they might have bought replacement stock. Comparatively, the presence of multiple genotypes on Farm 2 indicates that there may have been multiple introductions of the replacement stock from different herds. The unmonitored movement of animals from one herd to another poses a serious problem of disease transmission in most countries. In addition, WGS-SNP comparative analysis was able to discriminate the $B$. abortus S19 strains from the virulent strains, as well as illustrating that the vaccine strains are identical, despite their varying origin. Farmer's days and workshops to discuss the effects of the incorrect use of vaccines and the unapproved movement of animals from one herd to another are necessary measures that can supplement the available precautions and the brucellosis control and eradication programs, especially with the emerging small-scale farmers.

Supplementary Materials: Available online at https:/ /www.mdpi.com/2076-2607/9/3/570/s1: Table S1: Sample order used in Bruce-ladder (A) and AMOS (B) multiplex PCR assays and the descriptive information of the gel images, Table S2: Clean unique variants of the South African strains (refer to Table 2 for the sample names (in column 1) and sample ID (in column 2)). 
Author Contributions: Conceptualization: H.v.H. and M.B.L.; methodology: H.v.H., M.B.L., B.A.G., K.Z., A.J. and G.G.; software: M.B.L., B.A.G., A.J., F.M. and G.G.; validation: H.v.H., M.B.L., B.A.G., A.J., F.M. and G.G.; formal analysis: M.B.L., B.A.G., K.Z., A.J., F.M., G.G., G.P., P.L.M. and R.C.; investigation: M.B.L., B.A.G., I.M. and H.v.H.; resources: H.v.H., I.M., A.J., F.M., G.G., G.P., P.L.M. and R.C.; data curation: M.B.L., B.A.G., A.J., F.M. and G.G.; writing-original draft preparation: M.B.L.; writing—review and editing: H.v.H., B.A.G., I.M., A.J., F.M., G.G., G.P., P.L.M. and R.C.; visualization: M.B.L., B.A.G., A.J., F.M. and G.G.; supervision: H.v.H.; project administration: M.B.L., B.A.G. and H.v.H.; funding acquisition: H.v.H. and G.G. All authors have read and agreed to the published version of the manuscript.

Funding: This research was funded by the Gauteng Department of Agriculture and Rural Development (GDARD), National Research Foundation, South Africa, grant number 98652 and Institute of Tropical Medicine, Belgium, grant number FA4. The latter grant funded the APC.

Institutional Review Board Statement: The study was approved and conducted according to the Animal Ethics Committee of the University of Pretoria (V096-15; 30 October 2015) as well in terms of Section 20 of the Animal Disease Act, 1984 (ACT NO. 35 of 1984); for: Isolation and characterization of Brucella species within identified brucellosis positive herds (12/11/1/1/6).

Informed Consent Statement: Not applicable.

Data Availability Statement: All relevant data are within the paper and its supplementary information files.

Acknowledgments: Special acknowledgements to the ARC-OVR Bacteriology Section for the collaboration, Gauteng Department of Agriculture and Rural Development (GDARD), National Research Foundation (NRF), Institute of Tropical Medicine (ITM), Erasmus+ KA1 International Credit Mobility (ICM) exchange program, and University of Pretoria (UP) for the support and funding of the study. The authors also thank the Istituto Zooprofilattico Sperimentale del Mezzogiorno (IZSM), Teramo, Italy, for isolate sequencing, data analysis, and training, as well as the Bologna Biocomputing Group, University of Bologna, Italy, for training.

Conflicts of Interest: The authors declare no conflict of interest.

\section{References}

1. List of Prokaryotic Names with Standing in Nomenclature (LPSN). Species. Available online: http://www.bacterio.net/ -allnamesac.html (accessed on 1 August 2018).

2. De, B.K.; Stauffer, L.; Koylass, M.S.; Sharp, S.E.; Gee, J.E.; Helsel, L.O.; Steigerwalt, A.G.; Vega, R.; Clark, T.A.; Daneshvar, M.I.; et al. Novel Brucella strain (BO1) associated with a prosthetic breast implant infection. J. Clin. Microbiol. 2008, 46, 43-49. [CrossRef]

3. Scholz, H.C.; Nöckler, K.; Göllner, C.; Bahn, P.; Vergnaud, G.; Tomaso, H.; Al Dahouk, S.; Kämpfer, P.; Cloeckaert, A.; Maquart, M.; et al. Brucella inopinata sp. nov., isolated from a breast implant infection. Int. J. Syst. Evol. Microbiol. 2010, 60, 801-808. [CrossRef] [PubMed]

4. Scholz, H.C.; Revilla-Fernandez, S.; Al Dahouk, S.; Hammerl, J.A.; Zygmunt, M.S.; Cloeckaert, A.; Koylass, M.; Whatmore, A.M.; Blom, J.; Vergnaud, G.; et al. Brucella vulpis sp. nov., isolated from mandibular lymph nodes of red foxes (Vulpes vulpes). Int. J. Syst. Evol. Microbiol. 2016, 66, 2090-2098. [CrossRef] [PubMed]

5. Soler-Lloréns, P.F.; Quance, C.R.; Lawhon, S.D.; Stuber, T.P.; Edwards, J.F.; Ficht, T.A.; Robbe-Austerman, S.; O'Callaghan, D.; Keriel, A. A Brucella spp. isolate from a Pac-Man frog (Ceratophrys ornata) reveals characteristics departing from classical Brucellae. Front. Cell. Infect. Microbiol. 2016, 6, 116. [CrossRef]

6. Al Dahouk, S.; Köhler, S.; Occhialini, A.; Jiménez de Bagüés, M.P.; Hammer, J.A.; Eisenberg, T.; Vergnaud, G.; Cloeckaert, A.; Zygmunt, M.S.; Whatmore, A.M.; et al. Brucella spp. of amphibians comprise genomically diverse motile strains competent for replication in macrophages and survival in mammalian hosts. Sci. Rep. 2017, 7, 44420. [CrossRef] [PubMed]

7. Eisenberg, T.; Riße, K.; Schauerte, N.; Geiger, C.; Blom, J.; Scholz, H.C. Isolation of a novel 'atypical' Brucella strain from a bluespotted ribbontail ray (Taeniura lymma). Antonie Leeuwenhoek 2017, 110, 221-234. [CrossRef]

8. Mühldorfer, K.; Wibbelt, G.; Szentiks, C.A.; Fischer, D.; Scholz, H.C.; Zschöck, M.; Eisenberg, T. The role of 'atypical' Brucella in amphibians: Are we facing novel emerging pathogens? J. Appl. Microbiol. 2016, 122, 40-53. [CrossRef]

9. Pappas, G.; Papadimitriou, P.; Akritidis, N.; Christou, L.; Tsianos, E.V. The new global map of human brucellosis. Lancet Infect. Dis. 2006, 6, 91-99. [CrossRef]

10. McDermott, J.J.; Grace, D.; Zinsstag, J. Economics of brucellosis impact and control in low-income countries. Rev. Sci. Tech. Off. Int. Epiz. 2013, 32, 249-261. [CrossRef]

11. Spickler, A.R. Brucellosis: Brucella abortus. 2018. Available online: http://www.cfsph.iastate.edu/DiseaseInfo/factsheets.php (accessed on 1 January 2019). 
12. Samaha, H.; Al-Rowaily, M.; Khoudair, R.M.; Ashour, H.M. Multicenter study of brucellosis in Egypt. Emerg. Infect. Dis. 2008, 14, 1916-1918. [CrossRef] [PubMed]

13. Alvarez, J.; Suaez, J.L.; Garcia, N.; Serrat, C.; Perez-Sancho, M.; Gonzalez, S.; Ortega, M.J.; Gou, J.; Carbajo, L.; Garrido, F.; et al. Management of an outbreak of brucellosis due to B. melitensis in dairy cattle in Spain. Res. Vet. Sci. 2011, 90, $208-211$.

14. Ledwaba, B.; Mafofo, J.; van Heerden, H. Genome sequences of Brucella abortus and Brucella suis strains isolated from bovine in Zimbabwe. Genome Announc. 2014, 2, e01063-14. [CrossRef] [PubMed]

15. Godfroid, J.; Al Dahouk, S.; Pappas, G.; Roth, F.; Matope, G.; Muma, J.; Marcotty, T.; Pfeiffer, D.; Skjerve, E. A “One Health” surveillance and control of brucellosis in developing countries: Moving away from improvisation. Comp. Immunol. Microbiol. Infect. Dis. 2013, 36, 241-248. [CrossRef] [PubMed]

16. Bricker, B.J.; Halling, S.M. Differentiation of Brucella abortus bv. 1, 2, and 4, Brucella melitensis, Brucella ovis and Brucella suis bv. 1 by PCR. J. Clin. Microbiol. 1994, 32, 2660-2666. [CrossRef]

17. Bricker, B.J.; Halling, S.M. Enhancement of the Brucella AMOS PCR assay for differentiation of Brucella abortus vaccine strains S19 and RB51. J. Clin. Microbiol. 1995, 33, 1640-1642. [CrossRef] [PubMed]

18. Garcia-Yoldi, D.; Marin, C.M.; de Miguel, M.J.; Munoz, P.M.; Vizmanos, J.L.; Lopez-Goni, I. Multiplex PCR assay for the identification and differentiation of all Brucella species and the vaccine strains Brucella abortus S19 and RB51 and B. melitensis Rev1. Clin. Chem. 2006, 52, 779-781. [CrossRef]

19. Le Flèche, P.; Jacques, I.; Grayon, M.; Al Dahouk, S.; Bouchon, P.; Denoeud, F.; Nöckler, K.; Neubauer, H.; Guilloteau, L.A.; Vergnaud, G. Evaluation and selection of tandem repeat loci for a Brucella MLVA typing assay. BMC Microbiol. 2006, 6, 9. [CrossRef]

20. Al Dahouk, S.; Le Fleche, P.; Nockler, K.; Jacques, I.; Grayon, M.; Scholz, H.C.; Tomaso, H.; Vergnaud, G.; Neubauer, H. Evaluation of Brucella MLVA typing for human brucellosis. J. Microbiol. Methods 2007, 69, 137-145. [CrossRef]

21. Probert, W.S.; Schrader, K.N.; Khuong, N.Y.; Bystrom, S.L.; Graves, M.H. Real-Time multiplex PCR assay for detection of Brucella spp., B. abortus, and B. melitensis. J. Clin. Microbiol. 2004, 42, 1290-1293. [CrossRef] [PubMed]

22. DAFF-Department of Agriculture, Forestry and Fisheries. Policy Discussion Paper on the Review of Bovine Brucellosis Control. 2017. Available online: http:/ / www.daff.gov.za/vetweb/pamphlets\&Information/Policy/Discussion \%20paper $\% 20$ on $\% 20$ the $\%$ 20review\%20of\%20bovine\%20brucellosis\%20control_Final\%2005052017.pdf (accessed on 1 August 2018).

23. Bishop, G.C.; Bosman, P.P.; Herr, S. Bovine Brucellosis. In Infectious Diseases of Livestock with Special Reference to Southern Africa; Coetzer, J.A.W., Thomson, G.R., Tustin, R.C., Eds.; Oxford University Press: Cape Town, South Africa, 1994; Volume 3, pp. 1510-1527.

24. South African Veterinary Council. Annual Report Financial Statements April 2015-231 March 2016. Available online: https: //static.pmg.org.za/SAVC_Annual_Report_2015-2016.pdf (accessed on 1 August 2018).

25. Paulsen, I.T.; Seshadri, R.; Nelson, K.E.; Eisen, J.A.; Heidelberg, J.F.; Read, T.D.; Dodson, R.J.; Umayam, L.; Brinkac, L.M.; Beanan, M.J.; et al. The Brucella suis genome reveals fundamental similarities between animal and plant pathogens and symbionts. Proc. Natl. Acad. Sci. USA 2002, 99, 13148-13153. [CrossRef]

26. Foster, J.T.; Beckstrom-Sternberg, S.M.; Pearson, T.; Beckstrom-Sternberg, J.S.; Chain, P.S.; Roberto, F.F.; Hnath, J.; Brettin, T.; Keim, P. Whole-genome-based phylogeny and divergence of the genus Brucella. J. Bacteriol. 2009, 191, 2864-2870. [CrossRef]

27. Garofolo, G.; Di Giannatale, E.; Platone, I.; Zilli, K.; Sacchini, L.; Abass, A.; Ancora, M.; Cammà, C.; Di Donato, G.; De Massis, F.; et al. Origins and global context of Brucella abortus in Italy. BMC Microbiol. 2017, 17, 28. [CrossRef]

28. Foster, J.T.; Price, L.B.; Beckstrom-Sternberg, S.M.; Pearson, T.; Brown, W.D.; Kiesling, D.M.; Allen, C.A.; Liu, C.M.; BeckstromSternberg, J.; Roberto, F.F.; et al. Genotyping of Brucella species using clade specific SNPs. BMC Microbiol. $2012,12,110$. [CrossRef]

29. Moore, J.H. Bioinformatics. J. Cell. Physiol. 2007, 213, 365-369. [CrossRef]

30. Mariano, D.C.B.; Leite, C.; Santos, L.H.S.; Rocha, R.E.O.; de Melo-Minardi, R.C. A guide to performing systematic literature reviews in bioinformatics. arXiv 2007. Available online: https: / / arxiv.org/pdf/1707 (accessed on 1 February 2019).

31. Van der Auwera, G.A.; Carneiro, M.O.; Hartl, C.; Poplin, R.; Angel, G.D.; Levy-Moonshine, A.; Jordan, T.; Shakir, K.; Roazen, D.; Thibault, J.; et al. From FastQ Data to High-Confidence Variant Calls: The Genome Analysis Toolkit Best Practices Pipeline. Curr. Protoc. Bioinform. 2013, 43, 11.10.1-11.10.33.

32. Janowicz, A.; De Massis, F.; Ancora, M.; Cammà, C.; Patavino, C.; Battisti, A.; Prior, K.; Harmsen, D.; Holger Scholz, H.; Zilli, K.; et al. Core genome multi locus sequence typing and single nucleotide polymorphism analyses in the epidemiology of Brucella melitensis infections. J. Clin. Microbiol. 2018. [CrossRef] [PubMed]

33. Pightling, A.W.; Petronella, N.; Pagotto, F. Choice of reference sequence and assembler for alignment of Listeria monocytogenes short-read sequence data greatly influences rates of error in SNP Analyses. PLoS ONE. 2014, 9, e104579. [CrossRef] [PubMed]

34. Georgi, E.; Walter, M.C.; Pfalzgraf, M.T.; Northoff, B.H.; Holdt, L.M.; Scholz, H.C.; Zoeller, L.; Zange, S.; Antwerpen, M.H. Whole genome sequencing of Brucella melitensis isolated from 57 patients in Germany reveals high diversity in strains from Middle East. PLoS ONE. 2017, 12, e0175425. [CrossRef] [PubMed]

35. Ledwaba, M.B.; Ndumnego, O.C.; Matle, I.; Gelaw, A.K.; van Heerden, H. Investigating selective media for optimal isolation of Brucella spp. in South Africa. Onderstepoort J. Vet. Res. 2020, 87, 1-9. [CrossRef] 
36. World Organisation for Animal Health (OIE). Brucellosis (Infections with B. abortus, B. melitensis and B. suis). Manual of Diagnostic Tests and Vaccines for Terrestrial Animals; World Health Organization: Paris, France, 2016. Chapter 2.1.4. Available online: https://www.oie.int (accessed on 1 May 2018).

37. Keid, L.B.; Soares, R.M.; Vasconcellos, S.A.; Chiebao, D.P. A polymerase chain reaction for detection of Brucella canis in vaginal swabs of naturally infected bitches. Theriogenology 2007, 68, 1260-1270. [CrossRef]

38. Wood, D.E.; Salzberg, S.L. Kraken: Ultrafast metagenomic sequence classification using exact alignments. Genome Biol. 2014, 15, R46. [CrossRef] [PubMed]

39. Sahl, J.W.; Beckstrom-Sternberg, S.M.; Babic-Sternberg., J.S.; Gillece., J.D.; Hepp, C.M.; Auerbach, R.K.; Tembe, W.; Wagner, D.M.; Keim, P.S.; Pearson, T. The In Silico Genotyper (ISG): An open-source pipeline to rapidly identify and annotate nucleotide variants for comparative genomics applications. bioRxiv 2015. [CrossRef]

40. Li, H. Aligning sequence reads, clone sequences, and assembly contigs with BWA-MEM. arXiv 2013, arXiv:13033997.

41. McKenna, A.; Hanna, M.; Banks, E.; Sivachenko, A.; Cibulskis, K.; Kernytsky, A.; Garimella, K.; Altshuler, D.; Gabriel, S.; Daly, M.; et al. The Genome Analysis Toolkit: A MapReduce framework for analyzing next-generation DNA sequencing data. Genome Res. 2010, 20, 1297-1303. [CrossRef]

42. Gen Bank. Available online: https://www.ncbi.nlm.nih.gov/genbank/ (accessed on 1 August 2018).

43. Nascimento, M.; Sousa, A.; Ramirez, M.; Francisco, A.P.; Carrico, J.A.; Vaz, C. PHYLOViZ 2.0: Providing scalable data integration and visualization for multiple phylogenetic inference methods. Bioinformatics 2017, 33, 128-129. [CrossRef]

44. Swofford, D.L. PAUP* Phylogenetic Analysis Using Parsimony ( ${ }^{*}$ and Other Methods); Sinauer Associates: Sunderland, MA, USA, 2002.

45. Matope, G.; Bhebhe, E.; Muma, J.B.; Skjerve, E.; Djonne, B. Characterization of some Brucella species from Zimbabwe by biochemical profiling and AMOS-PCR. BMC Res. Notes 2009, 2, 261-267. [CrossRef] [PubMed]

46. Khames, M.; Mick, V.; de Miguel, M.J.; Girault, G.; Conde-Álvarez, R.; Khelef, D.; Oumouna, M.; Moriyón, I.; Muñoz, P.M.; Zúniga-Ripa, A. The characterization of Brucella strains isolated from cattle in Algeria reveals the existence of a B. abortus lineage distinct from European and Sub-Saharan African strains. Vet. Microbiol. 2017, 211, 124-128. [CrossRef] [PubMed]

47. Whatmore, A.M.; Koylass, M.S.; Muchowski, J.; Edwards-Smallbone, J.; Gopaul, K.K.; Perrett, L.L. Extended Multilocus Sequence Analysis to Describe the Global Population Structure of the Genus Brucella: Phylogeography and Relationship to Biovars. Front. Microbiol. 2017, 7, 2049. [CrossRef]

48. Bertu, W.J.; Ducrotoy, M.J.; Munoz, P.M.; Mick, V.; Zúniga-Ripa, A.; Bryssinckx, W.; Kwaga, J.K.; Kabir, J.; Welburn, S.C.; Moriyón, I.; et al. Phenotypic and genotypic characterization of Brucella strains isolated from autochthonous livestock reveals the dominance of B. abortus biovar 3a in Nigeria. Vet. Microbiol. 2015, 180, 103-108. [CrossRef] [PubMed]

49. Ducrotoy, M.; Bertu, W.J.; Matope, G.; Cadmus, S.; Conde-Álvarez, R.; Gusi, A.M.; Welburn, S.; Ocholi, R.; Blasco, J.M.; Moriyón, I. Brucellosis in Sub-Saharan Africa: Current challenges for management, diagnosis and control. Acta Trop. 2017, 165, 179-193. [CrossRef]

50. Nicoletti, P. Vaccination against Brucella. Adv. Biotevhnol. Process. 1990, 13, 147-168.

51. Schurig, G.G.; Sriranganathan, N.; Corbel, M.J. Brucellosis vaccines: Past, present and future. Vet. Microbiol. 2002, 90, 479-496. [CrossRef]

52. Ferreira, A.C.; Chambel, L.; Tenreiro, T.; Cardoso, R.; Flor, L.; Dias, I.T.; Pacheco, T.; Garin-Bastuji, B.; Le Flèche, P.; Vergnaud, G.; et al. MLVA16 typing of Portuguese human and animal Brucella melitensis and Brucella abortus Isolates. PLoS ONE 2012, 7, e42514. [CrossRef] [PubMed]

53. Simpson, G.J.G.; Marcotty, T.; Rouille, E.; Chilundo, A.; Letteson, J.J.; Godfroid, J. Immunological response to Brucella abortus strain 19 vaccination of cattle in a communal area in South Africa. J. S. Afr. Vet. Assoc. 2018, 89, e1-e7. [CrossRef] [PubMed]

54. Olsen, S.C.; Stoffregen, W.S. Essential role of vaccines in brucellosis control and eradication programs for livestock. Expert Rev. Vaccines 2005, 4, 915-928. [CrossRef]

55. Diaz, R.; Jones, L.M.; Leons, D.; Wilson, J.B. Surface antigens of smooth brucellae. J. Bacteriol. 1968, 96, 893-901. [CrossRef]

56. Tabynov, K.; Raskolnikov, S.; Kydyrbayev, Z.; Sansyzbay, A. Safety of the novel influenza viral vector Brucella abortus vaccine in pregnant heifers. Ciênc. Rural 2016, 46, 114-118. [CrossRef]

57. Nicoletti, P. Vaccination of cattle with Brucella abortus strain 19 administered by differing routes and doses. Vaccine 1984, 2, 133-135. [CrossRef]

58. Poester, F.P.; Ramos, E.T.; Gomes, M.J.P.; Chiminazzo, C.; Schurig, G. The serological response of adult cattle after vaccination with Brucella abortus strain 19 and RB51. Braz. J. Vet. Res. Anim. Sci. 2000, 37. [CrossRef]

59. Dean, A.S.; Crump, L.; Greter, H.; Schelling, E.; Zinsstag, J. Global burden of human brucellosis: A systematic review of disease frequency. PLoS Negl. Trop. Dis. 2012, 6, e1865. [CrossRef]

60. O'Callaghan, D.; Whatmore, A.M. Brucella genomics as we enter the multi-genome era. Brief. Funct. Genom. 2011, 10, 334-341. [CrossRef]

61. Whatmore, A.M.; Perrett, L.L.; MacMillan, A.P. Characterisation of the genetic diversity of Brucella by multilocus sequencing. BMC Microbiol. 2007, 7, 34. [CrossRef] [PubMed] 
62. Ma, J.Y.; Wang, H.; Zhang, X.F.; Xu, L.Q.; Hu, G.Y.; Jiang, H.; Zhao, F.; Zhao, H.Y.; Piao, D.R.; Qin, Y.M.; et al. MLVA and MLST typing of Brucella from Qinghai. China Infect. Dis. Poverty 2016, 13, 26. [CrossRef]

63. Zaki, N.A.; Salloum, T.; Osman, M.; Rafei, R.; Hamze, M.; Tokajian, S. Typing and comparative genome analysis of Brucella melitensis isolated from Lebanon. FEMS Microbiol. Lett. 2017, 364. [CrossRef] 